\title{
Medical research productivity in the Arab countries: 2007-2016 bibliometric analysis
}

\author{
Rola El Rassi ${ }^{1}$, \\ Lokman I Meho ${ }^{2}$, \\ Acile Nahlawi ${ }^{3}$, \\ Johnny S Salameh ${ }^{4}$, \\ Ali Bazarbachii, ${ }^{5,6}$, Elie A Akl ${ }^{1,5}$ \\ ${ }^{1}$ Clinical Research Institute, American \\ University of Beirut Medical Center, \\ Beirut, Lebanon \\ ${ }^{2}$ University Libraries, American \\ University of Beirut, Lebanon \\ ${ }^{3}$ American University of Beirut, \\ Lebanon \\ ${ }^{4}$ Department of Neurology, American \\ University of Beirut Medical Center, \\ Beirut, Lebanon \\ ${ }^{5}$ Department of Internal Medicine, \\ American University of Beirut Medical \\ Center, Beirut, Lebanon \\ ${ }^{6}$ Department of Anatomy, Cell Biology \\ and Physiological Sciences, American \\ University of Beirut Medical Center, \\ Beirut, Lebanon
}

Background The aim of this study was to assess recent trends in medical research productivity in Arab countries.

Methods We collected bibliometric data for the world countries, Arab countries, and Arab institutions for 2007-2016, using Essential Science Indicators, Journal Citation Reports, and Web of Science database. We collected the number of published papers overall and per year, citations per paper, and number of papers published in top quartile and top $10 \%$ journals. For the 10 most productive institutions, we additionally collected the number of papers with correspondence authors affiliated with the institution.

Results The Arab world produced 189 papers per one million people, about a quarter of the value for other world countries. Four Arab countries (Qatar, Tunisia, Lebanon, and Kuwait) produced more than 695 papers per one million people, exceeding the world average. The average number of citations per paper was 9.2; it rose to more than 15 for papers with international collaboration. At the institutional level, the number of citations showed upward trends, with six institutions having an average citation per paper higher than that of all Arab countries. For the 10 most productive institutions in Arab countries, the percentage of papers involving international collaborations ranged from $42 \%$ to $79 \%$; of these, $9 \%$ to $29 \%$ were led by authors from the same institution. For these 10 most productive institutions, the percentage of papers published in the top quartile journals and with a lead/corresponding author from the institution ranged from 7 to $32 \%$; that percentage drops to $1 \%$ to $10 \%$ for papers published in top $10 \%$ journals.

Conclusions Although medical research output in Arab countries at both the country and the institution levels has increased over the past 10 years, it is still lagging behind the rest of the world. The percentage of papers involving international collaborations was relatively high, but the majority of these papers were led by authors from outside the local institution, particularly when published in the top $10 \%$ journals.

\section{Correspondence to:}

Elie A. Akl, MD, MPH, PhD

Department of Internal Medicine

American University of Beirut Medical

Center

P.O. Box: 11-0236

Riad-El-Solh Beirut 11072020

Beirut

Lebanon

ea32@aub.edu.lb
Research in the medical sciences plays an important role in a country's economic growth, long-term sustainable development, and improvement in the standards of living and quality of life [1]. Governments across Europe as well as the United States have heeded these claims and have increased research spending in an effort to aide their ailing economies [1].

The situation is different in Arab countries however. Arab countries are lagging behind in the number of original research publications, number of publications in top journals and citation frequency [2], to name a few. The number of medical publications from Arab institutions in all 22 Arab countries between 1996 and 2012 was 76417 reports, which is equivalent to almost half that of Turkey 
and equal to only $4 \%$ of medical publications from United States based institutions [3]. This lag holds true across a number of other publications that have also assessed medical research in Arab countries and found it to be lagging $[2,4-6]$.

It is therefore essential to quantify current research output as it constitutes the basis for strategic planning and decisions making [7]. Bibliometric analysis, now a widely accepted method for assessing research in many fields, is employed to quantify and assess research output and also depict its growth and spread [8]. Comparisons of bibliometric characteristics between countries and institutions can reveal differences in research orientations, capacities, and collaboration patterns [9]. Additionally, universities and academic institutions increasingly rely on scientific analyses for making decisions regarding hiring, promotion, tenure, funding, and salary increases [9-13].

Published studies assessing medical research in Arab countries have mainly used PubMed to quantify productivity [2,4-6]. Since improving research productivity in Arab countries necessitates better understanding of its current status, we aim to assess more recent trends in medical research productivity in Arab countries, in terms of both quantity and quality using Essential Science Indicators, Journal Citation Reports, and Web of Science database.

\section{METHODS}

\section{Overall design}

This study compared medical research output: 1) between Arab countries combined and the rest of the world; 2) across individual Arab countries; and 3) across institutions in the region (hereafter referred to as "institutions").

\section{Eligibility criteria}

We used the following eligibility criteria:

- Countries: we included all 22 countries classified as Arab countries according to the Arab League [14];

- Institutions: we included the 10 most productive universities or research hospitals in Arab countries. We could have chosen a larger pool, for example, 15, 20, or 25, but that would have included institutions with less than 100 papers per year from 2007 to 2016, a number that might be too low to make accurate citation-based assessments;

- Research subject fields: we used data from the 8 broad medical fields as defined in Clarivate Analytics' Essential Science Indicators database, including: biology \& biochemistry, clinical medicine, immunology, microbiology, molecular biology \& genetics, neuroscience \& behavior, pharmacology \& toxicology, and psychiatry/psychology;

- Time period: we focused on the January 2007 - December 2016 time period to include enough data to make the findings reliable while reflecting the recent state of medical research in Arab countries;

- Types of documents: we included only 'article' and 'review' document types as classified by the Web of Science database. We excluded letters, editorials, abstracts and other types of documents. Of note, the Web of Science classifies 'case reports' as articles.

\section{Source of data}

We collected data in November 2017 using Essential Science Indicators, Journal Citation Reports, and Web of Science database. To identify all of eligible journals in the database, we used the 2007-2016 editions of Journal Citation Reports and included only those journals that were classified by Essential Science Indicators under the aforementioned eight broad subject categories. We included a total of 4530 journals (of which 421 ceased publication or changed names at some point during the period 2007-2016).

\section{Data collected}

We collected for each country the following data:

- Population size - using World Bank DataBank [15];

- Number of published papers per year;

- Number of papers with international collaboration for Arab countries; that is, papers that include at least two authors with respective affiliations from two different countries. We sub-categorized 
collaborations according to whether they are with: 1) Arab countries; 2) the European Union (including the United Kingdom); and 3) Canada and the United States;

- Citations per paper.

We also identified the top 25 medical research journals according to the number of papers published in those journals with at least one author affiliated with an institution from Arab countries, and specified their most recent impact factor scores.

We collected for the 10 most productive institutions in Arab countries the following data:

- Number of published papers per year;

- Citations per paper;

- Number of published papers involving international collaboration;

- Number of papers published in top quartile (Q1) and top 10\% journals in their respective fields, as classified by the Journal Citation Reports. These were identified as follows: We first identified the top 25\% and top 10\% journals in each of Journal Citation Reports' 200 plus subject areas and then matched the titles against the 4530 journals classified as medical research by Essential Science Indicators to come up with a list of top $25 \%$ and top $10 \%$ journals in medicine;

- Number of papers with correspondence authors affiliated with institutions in the Arab states.

\section{Data analysis}

For all analyses, we used the number of eligible publications over a 10-year period (2007-2016). The first set of analyses compared the research output of Arab countries as a whole to the world. We calculated for each country and for the Arab countries combined:

- World share: the percentage of papers published by the country out of the total number of papers published worldwide. For Arab countries, we calculated Arab world share which is the percentage of papers published by the country out of the total number of papers published by all Arab country researchers;

- Papers per 1 million people: which is equivalent to the number of papers published per country multiplied by 1000000 -population and divided by the population of that country;

- Percentage of world population: the percentage population of a country as compared to the world;

- Total number of papers published during 2007-2016 and per year for Arab countries combined and other world countries;

For Arab countries alone, we calculated:

- The percentage of papers produced through international collaborations with other Arab countries, countries from the European Union, and North America for each country and for the Arab countries combined;

- Citation rate stratified by whether paper involved an international collaboration or not.

The second set of analyses compared the research output of institutions in Arab countries. We calculated for each institution:

- Total number of papers published during 2007-2016 for 10 most productive Arab institutions;

- Percent national contribution: the percentage of papers published by the institution out of the total number of papers published in the respective country;

- Percentage of papers published in top quartile (Q1) and top 10\% journals in their respective fields;

- Percentage of published papers involving international collaborations;

- Percentage of papers with correspondence authors affiliated with these institutions; and then stratified by percentage of papers published in top quartile (Q1) and top 10\% journals.

We did not explore the distribution of our data due to its huge size and the limitations in extraction; extracted as a lump rather than separate variables. We therefore calculated averages where applicable.

\section{RESULTS}

\section{Arab counties vs world}

We identified a total of 76978 papers published by research groups in Arab countries between 2007 and 2016. Table 1 shows the medical research output for the top 25 world countries, ranked in descending 
Table 1. Medical research output by world countries; 2007-2016; countries ranked in descending order by papers per 1 million people and limited to first 25 countries

Rank Countriles Papers per country* World share Populationt \% of world population Papers per 1 million Citations per paper*

\begin{tabular}{|c|c|c|c|c|c|c|c|}
\hline 1 & Switzerland & 106969 & $2.2 \%$ & 8372098 & $0.11 \%$ & 12777 & 23.7 \\
\hline 2 & Denmark & 65119 & $1.3 \%$ & 5731118 & $0.08 \%$ & 11362 & 22.4 \\
\hline 3 & Netherlands & 170420 & $3.5 \%$ & 17018408 & $0.23 \%$ & 10014 & 22.8 \\
\hline 4 & Sweden & 98873 & $2.0 \%$ & 9903122 & $0.13 \%$ & 9984 & 21.6 \\
\hline 5 & Australia & 189549 & $3.8 \%$ & 24127159 & $0.32 \%$ & 7856 & 18.4 \\
\hline 6 & Belgium & 79630 & $1.6 \%$ & 11348159 & $0.15 \%$ & 7017 & 22.9 \\
\hline 7 & Canada & 247172 & $5.0 \%$ & 36286425 & $0.49 \%$ & 6812 & 20.7 \\
\hline 8 & United Kingdom & 424060 & $8.6 \%$ & 65637239 & $0.88 \%$ & 6461 & 22.7 \\
\hline 9 & Israel & 54758 & $1.1 \%$ & 8547100 & $0.11 \%$ & 6407 & 18.8 \\
\hline 10 & Austria & 54654 & $1.1 \%$ & 8747358 & $0.12 \%$ & 6248 & 20.3 \\
\hline 11 & United States & 1659565 & $33.7 \%$ & 323127513 & $4.34 \%$ & 5136 & 21.3 \\
\hline 12 & Germany & 383518 & $7.8 \%$ & 82667685 & $1.11 \%$ & 4639 & 19.3 \\
\hline 13 & Italy & 246987 & $5.0 \%$ & 60600590 & $0.81 \%$ & 4076 & 18.4 \\
\hline 14 & Greece & 42761 & $0.9 \%$ & 10746740 & $0.14 \%$ & 3979 & 16.2 \\
\hline 15 & France & 236511 & $4.8 \%$ & 66896109 & $0.90 \%$ & 3535 & 20.0 \\
\hline 16 & Spain & 162440 & $3.3 \%$ & 46443959 & $0.62 \%$ & 3498 & 17.1 \\
\hline 17 & Taiwan & 75670 & $1.5 \%$ & 23500000 & $0.32 \%$ & 3220 & 11.6 \\
\hline 18 & South Korea & 157790 & $3.2 \%$ & 51245707 & $0.69 \%$ & 3079 & 11.0 \\
\hline 19 & Japan & 313600 & $6.4 \%$ & 126994511 & $1.71 \%$ & 2469 & 13.9 \\
\hline 20 & Poland & 63534 & $1.3 \%$ & 37948016 & $0.51 \%$ & 1674 & 11.7 \\
\hline 21 & Turkey & 106279 & $2.2 \%$ & 79512426 & $1.07 \%$ & 1337 & 6.4 \\
\hline 22 & Brazil & 135175 & $2.7 \%$ & 207652865 & $2.79 \%$ & 651 & 10.0 \\
\hline 23 & Iran & 50479 & $1.0 \%$ & 80277428 & $1.08 \%$ & 629 & 6.6 \\
\hline \multirow[t]{2}{*}{24} & China & 448360 & $9.1 \%$ & 1378665000 & $18.53 \%$ & 325 & 9.4 \\
\hline & Arab countries & 76978 & $1.6 \%$ & 406452690 & $5.46 \%$ & 189 & 9.2 \\
\hline \multirow[t]{2}{*}{25} & India & 126029 & $2.6 \%$ & 1324171354 & $17.79 \%$ & 95 & 9.3 \\
\hline & WORLD (excluding Arab countries) & 4892030 & & 7035682888 & $94.54 \%$ & 695 & 15.1 \\
\hline
\end{tabular}

*Source: Essential Science Indicators (October 1, 2017 edition), covering papers and citations for the period January 1, 2007 - August 31, 2017. †Source: World Bank DataBank.

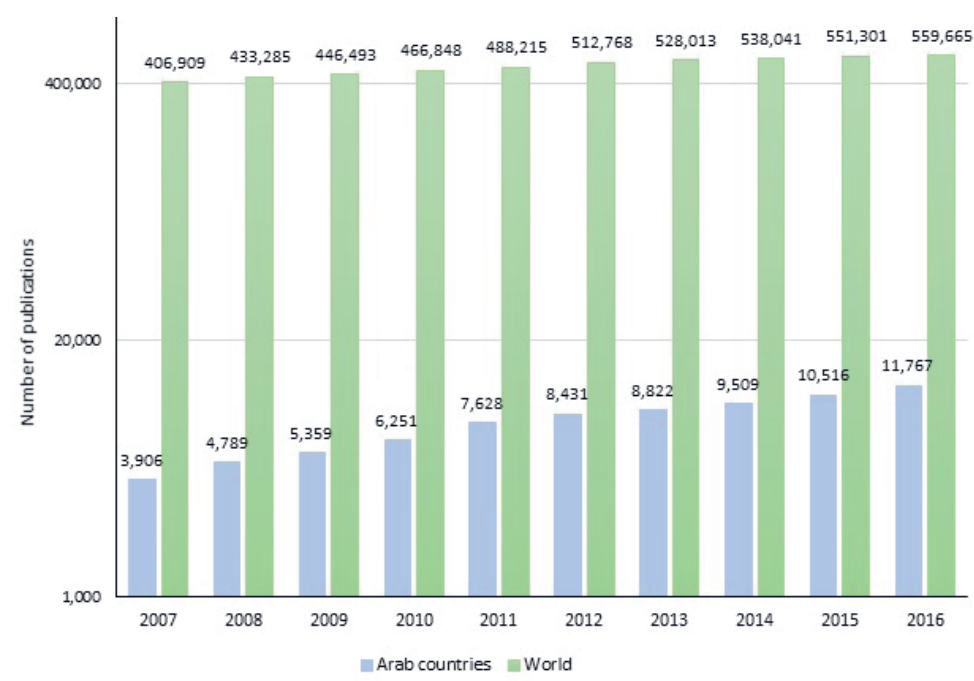

Figure 1. Number of publications in medical research in the Arab countries as a whole vs the world per year between 2007and 2016 . order by papers per million people, and for all Arab countries combined. The papers published in Arab countries as a whole constituted 1.6\% of the world output. As for the number of papers per million people, research groups in Arab countries published 189 papers per one million people as compared to 695 papers per one million by researchers in all world countries, excluding Arab countries.

Figure 1 further depicts the trend of medical research productivity in number of papers per year in Arab countries combined and in the world. The productivity of researchers in Arab countries has increased 3-fold between 2007 and 2016.

\section{Arab countries amongst each other}

Table 2 shows the medical research output of researchers in individual Arab countries. Research groups from Qatar, Tunisia, Lebanon, and Kuwait

(in descending order) had a total number of papers per one million people above the world average of 695 papers per million. The number of citations per paper was higher than the world average of $15.1 \mathrm{in}$ Sudan alone. Arab countries that had publications with a citation rate higher than that of all Arab countries combined were in descending order Sudan, Lebanon, United Arab Emirates, Qatar, Oman, Saudi Arabia, Jordan and Iraq 
Table 2. Medical research output of all Arab countries 2007-2016; countries ranked in descending order by papers per 1 million people

\begin{tabular}{|c|c|c|c|c|c|}
\hline Worlo Rank & Countriles & Papers Per country* & Arab WORLD SHARE & Papers per 1 millon & Citations per paper* \\
\hline 69 & Qatar & 2971 & $3.9 \%$ & 1156 & 11.4 \\
\hline 50 & Tunisia & 8769 & $11.4 \%$ & 769 & 8.4 \\
\hline 54 & Lebanon & 4504 & $5.9 \%$ & 750 & 13.4 \\
\hline 71 & Kuwait & 2862 & $3.7 \%$ & 706 & 8.7 \\
\hline 39 & Saudi Arabia & 21897 & $28.4 \%$ & 678 & 9.6 \\
\hline 108 & Bahrain & 682 & $0.9 \%$ & 479 & $\mathrm{NR} \dagger$ \\
\hline 58 & United Arab Emirates & 3927 & $5.1 \%$ & 424 & 12.1 \\
\hline 62 & Jordan & 3592 & $4.7 \%$ & 380 & 9.5 \\
\hline 85 & Oman & 1527 & $2.0 \%$ & 345 & 11.1 \\
\hline 36 & Egypt & 24692 & $32.1 \%$ & 258 & 7.8 \\
\hline 113 & Palestine & 613 & $0.8 \%$ & 128 & $\mathrm{NR} \dagger$ \\
\hline 56 & Morocco & 4027 & $5.2 \%$ & 114 & 7.3 \\
\hline 119 & Libya & 561 & $0.7 \%$ & 89 & $\mathrm{NR} \dagger$ \\
\hline 80 & Algeria & 1902 & $2.5 \%$ & 47 & 9.1 \\
\hline 106 & Syria & 710 & $0.9 \%$ & 39 & $\mathrm{NR} \dagger$ \\
\hline 186 & Djibouti & 36 & $0.0 \%$ & 38 & $\mathrm{NR} \dagger$ \\
\hline 90 & Iraq & 1279 & $1.7 \%$ & 34 & 9.3 \\
\hline 89 & Sudan & 1280 & $1.7 \%$ & 32 & 16.7 \\
\hline 198 & Comoros & 19 & $0.0 \%$ & 24 & $\mathrm{NR} \dagger$ \\
\hline 120 & Yemen & 529 & $0.7 \%$ & 19 & $\mathrm{NR} \dagger$ \\
\hline 178 & Mauritania & 58 & $0.1 \%$ & 13 & $\mathrm{NR} \dagger$ \\
\hline 192 & Somalia & 24 & $0.0 \%$ & 2 & $\mathrm{NR} \dagger$ \\
\hline TOTAL & ARAB COUNTRIES & 76978 & $100.0 \%$ & 189 & 9.2 \\
\hline
\end{tabular}

NR - not reported.

*Source: Essential Science Indicators (October 1, 2017 edition), covering papers and citations for the period January 1, 2007 August 31, 2017.

$\uparrow$ Not reported because the number of papers published by the country was too small to accurately calculate its citation rate.

Fifty one percent of papers published by research groups in Arab countries did not involve any international collaborations (Table 3) and had an average of 5.4 citations per paper. Twenty seven percent of papers involved collaborations with the European Union and 19\% with Canada and United States, with an average citation rate of 14.8 per paper and 18.2 per paper, respectively. Researchers in Qatar, United Arab Emirates, Saudi Arabia, Lebanon, Jordan and Egypt - in descending order - collaborated with Europe and Canada and the United States on more than $50 \%$ of their publications. Researchers in Arab countries mostly submitted their publications to journals of low impact; only four of those journals ranked in the

Table 3. Collaborations by individual Arab countries; 2007-2016; countries ranked in descending order by total research output*

\begin{tabular}{|c|c|c|c|c|c|c|c|c|c|c|c|c|}
\hline \multirow[b]{3}{*}{ Country $\dagger$} & \multirow{2}{*}{\multicolumn{2}{|c|}{ TOtAL RESEARCH OUTPUt }} & \multirow{2}{*}{\multicolumn{2}{|c|}{$\begin{array}{l}\text { Papers WITHOUt } \\
\text { INTERNATIONAL } \\
\text { COLLABORATION }\end{array}$}} & \multicolumn{8}{|c|}{ Papers WITH INTERNATIONAL COLLABORATION WITH } \\
\hline & & & & & \multicolumn{2}{|c|}{$\begin{array}{l}\text { other Arab } \\
\text { countries }\end{array}$} & \multicolumn{2}{|c|}{ European Union } & \multicolumn{2}{|c|}{$\begin{array}{l}\text { Canada and } \\
\text { United States }\end{array}$} & \multicolumn{2}{|r|}{ Overall } \\
\hline & $\begin{array}{l}\text { Papers per } \\
\text { country }\end{array}$ & $\begin{array}{c}\text { Citations } \\
\text { per paper } \dagger\end{array}$ & $\%$ & $\begin{array}{c}\text { Citations } \\
\text { per paper } \dagger\end{array}$ & $\%$ & $\begin{array}{c}\text { Citations } \\
\text { per paper } \dagger\end{array}$ & $\%$ & $\begin{array}{c}\text { Citations } \\
\text { per paper } \dagger\end{array}$ & $\%$ & $\begin{array}{c}\text { Citations } \\
\text { per paper } \dagger\end{array}$ & $\%$ & $\begin{array}{c}\text { Citations } \\
\text { per paper* }\end{array}$ \\
\hline Egypt & 24692 & 8.3 & 49 & 6.0 & 21 & 8.1 & 18 & 16.2 & 16 & 16.9 & 51 & 10.8 \\
\hline Saudi Arabia & 21897 & 9.7 & 32 & 5.4 & 25 & 8.5 & 21 & 18.5 & 23 & 21.2 & 68 & 12.0 \\
\hline Tunisia & 8769 & 8.3 & 55 & 5.1 & 9 & 18.2 & 37 & 14.1 & 6 & 34.0 & 45 & 12.8 \\
\hline Lebanon & 4504 & 15.0 & 36 & 8.1 & 15 & 26.0 & 34 & 26.4 & 33 & 27.4 & 64 & 19.3 \\
\hline Morocco & 4027 & 7.7 & 59 & 3.1 & 9 & 30.9 & 33 & 16.2 & 8 & 36.0 & 41 & 14.8 \\
\hline United Arab Emirates & 3927 & 13.2 & 23 & 7.2 & 21 & 15.6 & 36 & 21.0 & 30 & 24.1 & 77 & 15.2 \\
\hline Jordan & 3592 & 11.2 & 46 & 6.1 & 18 & 22.4 & 21 & 27.1 & 23 & 26.9 & 54 & 16.0 \\
\hline Qatar & 2971 & 12.5 & 15 & 7.6 & 22 & 20.4 & 47 & 18.2 & 36 & 20.8 & 85 & 13.6 \\
\hline Arab world & 76978 & 9.2 & 51 & 5.4 & - & - & 27 & 14.8 & 19 & 18.2 & 49 & 13.0 \\
\hline
\end{tabular}

*This table is limited to the 8 most published countries with most research output. The papers by other countries are too few to accurately examine the impact of their international collaborations.

†Source: Web of Science (November 2017), covering papers for the period 2007-2016 cited from January 2007 up to November 2017. 
top quartile and only five have an impact factor above 3.0 (Table 4). Also, only 24\% of Arab countries' papers are published in top quartile journals in comparison to $38 \%$ for the rest of the world.

\section{Institutions in Arab countries}

The ten most productive institutions in the Arab countries are listed in Table 5. These institutions were from Egypt $(n=4)$, Saudi Arabia $(n=3)$, Lebanon $(n=1)$, Kuwait $(n=1)$, and Tunisia $(n=1)$. Research groups from the Kuwait University in Kuwait and the American University of Beirut in Lebanon had a greater than $50 \%$ share of research productivity contribution per country. Papers published by six of the 10 most productive institutions had an average citation per paper higher than that of Arab countries as a whole; none had an average citation per paper higher than world average. Figure 2 depicts the produc-

Table 4. List of the top 25 medical research journals in which researchers from Arab countries publish, ranked in descending order by number of papers published with at least one author affiliated with an institution from the Arab countries

\begin{tabular}{clccc}
\hline RANKK & NaME Of JOURNAL & NUMBER OF PAPERS & QUARTIIE & IF* \\
\hline 1 & Saudi Medical Journal & 1412 & 4 & 0.709 \\
\hline 2 & Life Science Journal - Acta Zhengzhou University Overseas Edition & 903 & 4 & 0.165 \\
\hline 3 & Annals of Saudi Medicine & 580 & 4 & 0.558 \\
\hline 4 & African Journal of Biotechnology & 444 & 4 & 0.573 \\
\hline 5 & Parasitology Research & 431 & 2 & 2.329 \\
\hline 6 & Biomed Research International & 361 & 2 & 2.476 \\
\hline 7 & Medical Principles and Practice & 332 & 2 & 1.469 \\
\hline 8 & Natural Product Research & 328 & 3 & 1.828 \\
\hline 9 & African Journal of Microbiology Research & 327 & 4 & 0.539 \\
\hline 10 & Medicinal Chemistry Research & 312 & 4 & 1.277 \\
\hline 11 & International Journal of Biological Macromolecules & 308 & 1 & 3.671 \\
\hline 12 & Kuwait Medical Journal & 307 & 4 & 0.089 \\
\hline 13 & Neurosciences & 302 & 4 & 0.552 \\
\hline 14 & Archives de Pediatrie & 299 & 4 & 0.372 \\
\hline 15 & Saudi Journal of Biological Sciences & 292 & 2 & 2.564 \\
\hline 16 & Asian Pacific Journal of Cancer Prevention & 246 & 3 & 2.514 \\
\hline 17 & Natural Product Communications & 243 & 4 & 0.773 \\
\hline 18 & International Journal of Pharmaceutics & 236 & 1 & 3.061 \\
\hline 19 & Journal of Infection in Developing Countries & 235 & 4 & 1.353 \\
\hline 20 & Cochrane Database of Systematic Reviews & 227 & 1 & 6.264 \\
\hline 21 & Bioresource Technology & 225 & 1 & 5.651 \\
\hline 22 & Pakistan Journal of Medical Sciences & 224 & 3 & 0.696 \\
\hline 23 & Annales de Biologie Clinique & 224 & 4 & 0.225 \\
\hline 24 & Saudi Pharmaceutical Journal & 214 & 3 & 2.302 \\
\hline 25 & World Journal of Gastroenterology & 208 & 2 & 3.365 \\
\hline & & & 4 \\
\hline
\end{tabular}

IF - 2015 impact factor

Table 5. Percent national contribution and citations per paper of the 10 most productive institutions in Arab countries between 2007 and 2016; countries ranked in descending order of the number of citations per paper

\begin{tabular}{|c|c|c|c|c|c|}
\hline Rank & InSTITUTION AND COUNTRY & $\begin{array}{l}\text { Papers PER } \\
\text { INSTITUTION }\end{array}$ & $\begin{array}{c}\text { Papers per } \\
\text { Country }\end{array}$ & $\begin{array}{c}\text { Percent mational } \\
\text { contribution }\end{array}$ & $\begin{array}{l}\text { Citations } \\
\text { PER PAPER }^{*}\end{array}$ \\
\hline 1 & American University of Beirut - Lebanon & 2794 & 4433 & 63 & 13.8 \\
\hline 2 & King Abdulaziz University - Saudi Arabia & 4151 & 21897 & 19 & 13.0 \\
\hline 3 & King Faisal Specialist Hospital \& Research Centre - Saudi Arabia & 2057 & 21897 & 9 & 12.7 \\
\hline 4 & Kuwait University - Kuwait & 1862 & 2862 & 65 & 10.4 \\
\hline 5 & Cairo University - Egypt & 5750 & 24692 & 23 & 9.5 \\
\hline 6 & Mansoura University - Egypt & 2803 & 24692 & 11 & 9.3 \\
\hline 7 & Ain Shams University - Egypt & 3089 & 24692 & 13 & 9.0 \\
\hline 8 & Alexandria University - Egypt & 2345 & 24692 & 9 & 8.8 \\
\hline 9 & King Saud University - Saudi Arabia & 8623 & 21897 & 39 & 8.3 \\
\hline 10 & Universite de Tunis El Manar - Tunisia & 2998 & 8769 & 34 & 8.0 \\
\hline
\end{tabular}

*Source: Web of Science (November 2017), covering papers for the period 2007 - 2016 cited from January 2007 up to November 2017. 


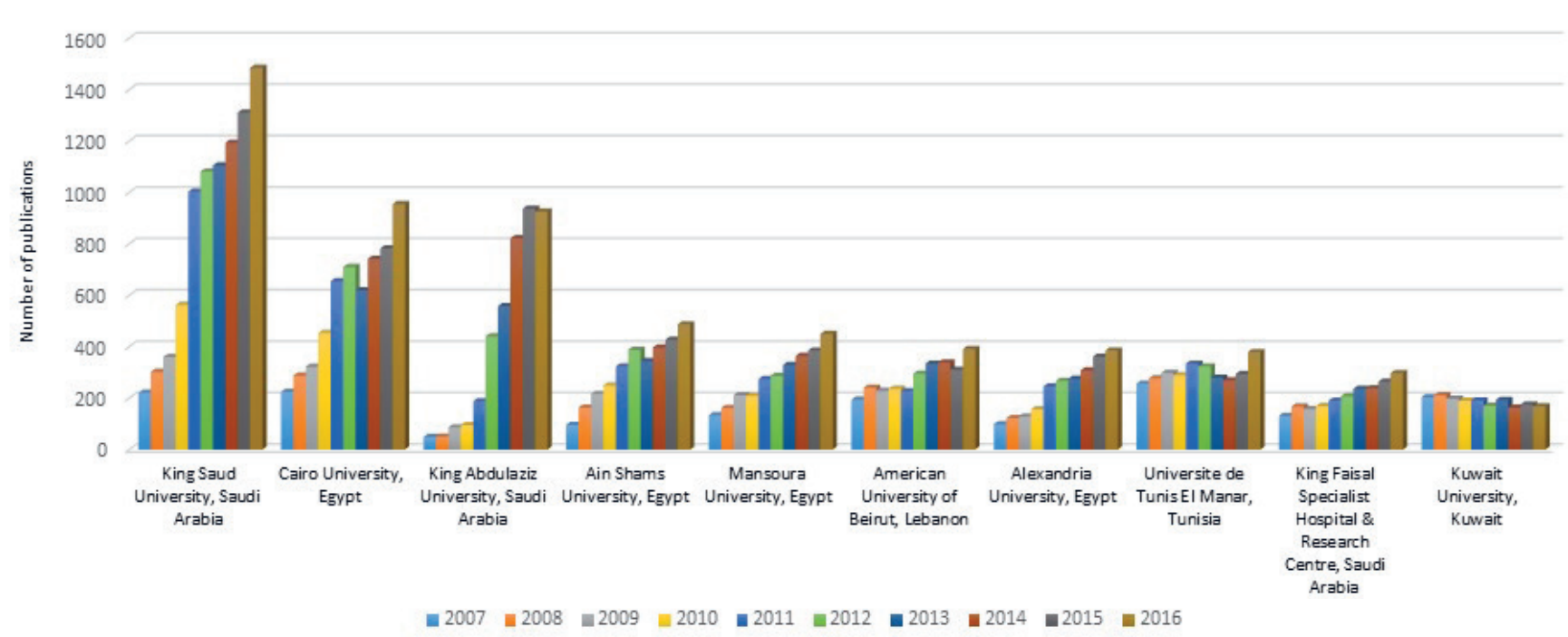

Figure 2. Number of publications in medical research across the years of the 10 most productive institutions in Arab countries.

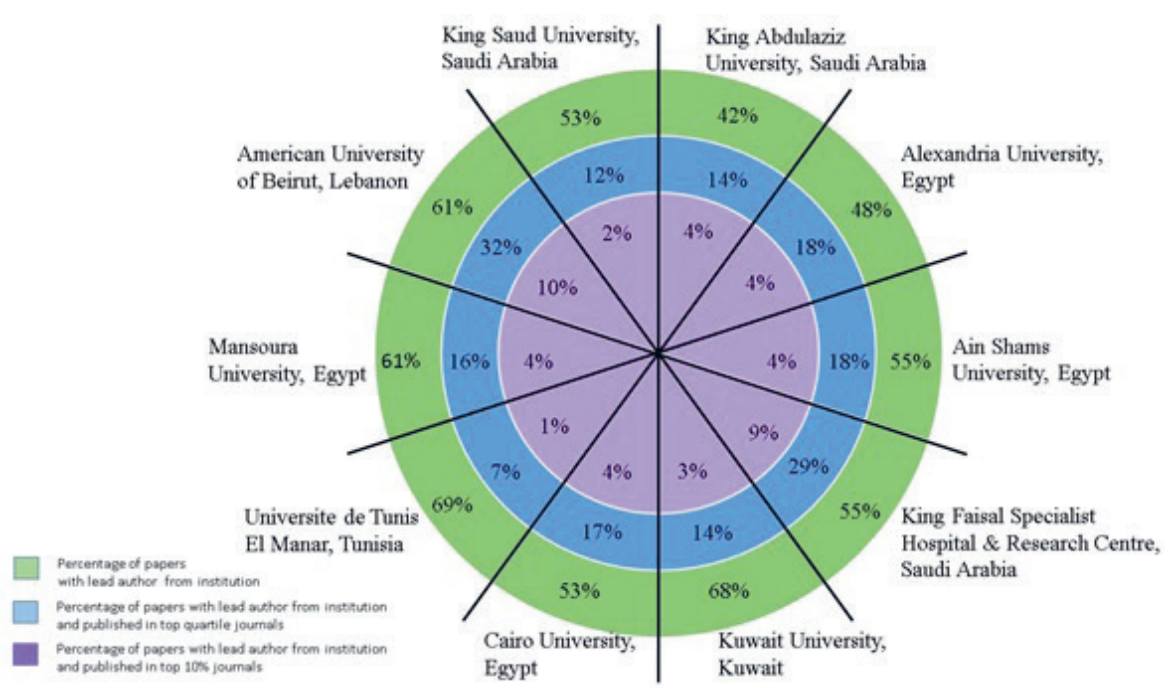

Figure 3. Percentages of papers with lead/correspondence author from institution (green band), published in first quartile journals (blue band), and published in the top 10\% journals (purple band) for the 10 most productive institutions in Arab countries. Surface area is not proportional to percentage and institutions have not been ranked in any specific order. tivity trend in medical research of researchers in these institutions. Almost all institutions showed upward trend, although to different degrees. Research productivity of groups at Kuwait University in Kuwait showed an almost stagnant trend.

The research output of four institutions ranked higher than the average of Arab countries as a whole in the percentage of papers published in top quartile journals (Table 6). More than $10 \%$ of papers produced by researchers at King Faisal Specialist Hospital \& Research Centre in Saudi Arabia and the American University of Beirut in Lebanon were published in top 10\% journals (Table 6).

The percentage of papers with lead/ correspondence author from the

Table 6. Percentage of papers in first quartile (Q1) and top 10\% journals of the ten most productive institutions in Arab countries between 2007 and 2016; countries ranked in descending order by percentage of top 10\% papers

\begin{tabular}{|c|c|c|c|c|}
\hline Rank & IMSTIIUTIION AND COUNTRY & $\begin{array}{l}\text { PaperRs PER } \\
\text { INSTITUTION }\end{array}$ & $\begin{array}{l}\text { Percentage of papers } \\
\text { IN } 01 \text { Journals }\end{array}$ & $\begin{array}{l}\text { Percentage OF PAPERS } \\
\text { IN TOP } 10 \% \text { JOURnals }\end{array}$ \\
\hline 1 & King Faisal Specialist Hospital \& Research Centre - Saudi Arabia & 2057 & 35 & 13.1 \\
\hline 2 & American University of Beirut - Lebanon & 2794 & 36 & 12.7 \\
\hline 3 & King Abdulaziz University - Saudi Arabia & 4151 & 29 & 9.6 \\
\hline 4 & Alexandria University - Egypt & 2345 & 24 & 7.2 \\
\hline 5 & Cairo University - Egypt & 5750 & 23 & 6.9 \\
\hline 6 & King Saud University - Saudi Arabia & 8623 & 22 & 6.6 \\
\hline 7 & Mansoura University - Egypt & 2803 & 21 & 6.4 \\
\hline 8 & Kuwait University - Kuwait & 1862 & 20 & 5.9 \\
\hline 9 & Ain Shams University - Egypt & 3089 & 22 & 5.7 \\
\hline 10 & Universite de Tunis El Manar - Tunisia & 2998 & 13 & 4.4 \\
\hline
\end{tabular}




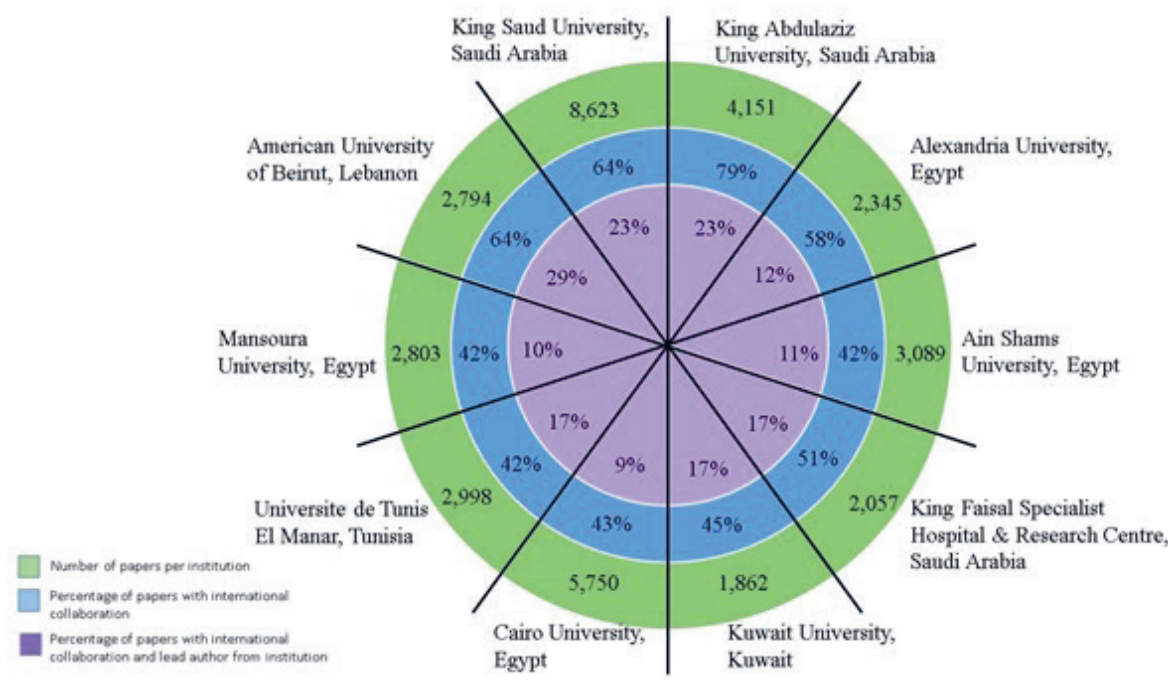

Figure 4. Papers with international collaboration for the 10 most productive institutions in Arab countries (green band), with percentage with international collaboration (blue band), and percentage with both international collaboration and lead authorship from the institution (purple band). Surface area is not proportional to percentage and institutions have not been ranked in any specific order. The percentage of papers with international collaboration and lead/correspondence author from institution was calculated from the total number of papers per institution. same institution was higher than 50\% in eight Arab institutions (Figure 3). Only two of these institutions' researchers had more than $20 \%$ of their papers published in top quartile journals. Researchers from one institution only had more than $10 \%$ of their papers published in the top $10 \%$ journals.

Figure 4 illustrates the international collaborations between research groups for the ten most productive institutions, which ranged from $42 \%$ to $79 \%$ across the 10 institutions. The percentage of papers involving international collaborations and led by authors from the same institution ranged between 9\% and $29 \%$ across the 10 institutions.

\section{DISCUSSION}

In summary, this study used bibliometric indicators to describe medical research productivity in 22 Arab countries during the last decade. Over the 2007-2016 time period, the number of medical research publications per one million people for researchers in Arab countries was almost about a fourth of that of the world. However, medical research productivity has been increasing in these countries at a faster rate, relative to the rest of the world during the same time period.

The study has a number of strengths. First, and to our knowledge, this is the first article to analyze the quality and quantity of medical research in Arab countries using bibliographic resources such as Essential Science Indicators, Journal Citation Reports, and Web of Science database. Previous studies on research productivity in Arab countries have mainly used the Medline database [2-6]. Nonetheless, our finding of paucity in medical research productivity is consistent with the findings of those studies [2-6]. Second, we adjusted the raw counts of publications by population number to avoid misleading results. As such, our study showed that productivity is higher in small countries, such as Qatar, Tunisia, Kuwait and Lebanon than in Saudi Arabia and Egypt. Other investigators reported similar findings for small countries when adjusting for population size $[4,5]$.

The study also has a number of limitations. Although we included papers from a sizeable number of medical research journals (as classified by Essential Science Indicators), there is probably a number of local medical journals that were not captured by the used databases. However, we believe that including more journals would increase the numbers but in a proportional way that would not affect the interpretation of the results. Finally, the inclusion of "case reports" in this study (given the Web of Science classifies them as articles) could have lowered the number of citations per papers, particularly since major journals do not accept to publish case reports.

One of our major findings is the paucity in medical research productivity in Arab countries. Reasons stipulated to explain this paucity include political instability in these countries, regional conflicts [5], lack of proper research infrastructure and equipment [3], lack of freedom and democracy, brain drain, lack of funding, and difficulty of publishing in high impact journals [16,17].

At the institutional level, almost all institutions showed upward trends, although to different degrees, with six of them having average citations per paper higher than that of Arab countries as a whole. The ranking of these institutions changes when focusing on quality as opposed to quantity indicators. 
It is noteworthy that papers involving international collaborations had a 3-fold higher citation rate than those not involving international collaborations. This is consistent with findings from a number of other studies conducted in other settings [18-20]. This finding highlights the importance of international collaboration, particularly when considering advantages such as increased visibility, and more opportunities for securing funding.

Researchers in Arab countries collaborate primarily with the United States and Canada and countries in the European Union, which could mostly be due to having received their education or training in said countries. The intriguing finding was that a relatively small percentage of papers involving collaboration and published in top journals, were led by authors from local institutions. This raises concerns about institutions in Arab countries offering affiliations to international investigators as a way to improve their medical research productivity metrics.

There is a need to maintain the momentum of increasing number of publications while improving their quality. Capacity building in conducting medical research would be essential for that purpose. Oliver et al. (2015) has proposed conducting capacity building at the levels of individuals, research teams, organizations, and country wide. Although that approach was conceived for systematic reviews, it does apply to the wider research field [21].

Additional national level policies to enhance medical research could include strengthening national funding programs and building the research infrastructure (including regulatory and supervisory bodies). While there are many reasons for institutions to pursue regional as well as international research collaborations, a possible increase in citation rate would be an extra advantage. Other institutional level interventions include instatement of tenure, intramural funding programs, establishing doctoral and postdoctoral programs, and faculty compensation schemes that incentivize research $[12,13]$.

Institutions and authors can also use social media to disseminate their research output. The use of social media will benefit both the institution and the author by making the publications easier to find and access [22] and presumably increase citation impact [23]. A study by Thelwall et al (2013) evaluated the impact of specific altmetrics on citation rate and provided strong evidence that six of the 11 altmetrics assessed (tweets, Facebook wall posts, research highlights, blog mentions, mainstream media mentions and forum posts) associated with citation counts, at least in medical and biological sciences [24].

\section{CONCLUSIONS}

Although the medical research output of Arab countries has increased over the past 10 years, it is still lagging behind the rest of the world. There is a need for systemic interventions at the country and institutional levels to maintain the momentum and improve the quality of the output. 
1 Macilwain C. Science economics: What science is really worth. Nature. 2010;465:682-4. Medline:20535177 doi:10.1038/465682a

2 Benamer HT, Bakoush O. Arab nations lagging behind other Middle Eastern countries in biomedical research: a comparative study. BMC Med Res Methodol. 2009;9:26. Medline:19374747 doi:10.1186/1471-2288-9-26

3 El-Azami-El-Idrissi M, Lakhdar-Idrissi M, Ouldim K, Bono W, Amarti-Riffi A, Hida M, et al. Improving medical research in the Arab world. Lancet. 2013;382:2066-7. Medline:24360385 doi:10.1016/S0140-6736(13)62692-6

4 Bredan A, Benamer H, Bakoush O. Visibility of Arab countries in the world biomedical literature. Libyan J Med. $2011 ; 6: 1$. Medline:21526038

5 Tadmouri GO, Bissar-Tadmouri N. Biomedical publications in an unstable region: the Arab world, 1988-2002. Lancet. 2003;362:1766. Medline:14643139 doi:10.1016/S0140-6736(03)14868-4

6 Al-Maawali A, Al Busadi A, Al-Adawi S. Biomedical publications profile and trends in gulf cooperation council countries. Sultan Qaboos Univ Med J. 2012;12:41-7. Medline:22375257 doi:10.12816/0003086

7 Meo SA, Usmani AM, Vohra MS, Bukhari IA. Impact of GDP, spending on R\&D, number of universities and scientific journals on research publications in pharmacological sciences in Middle East. Eur Rev Med Pharmacol Sci. 2013;17:2697705. Medline:24174349

8 Durieux V, Gevenois PA. Bibliometric indicators: quality measurements of scientific publication. Radiology. 2010;255:34251. Medline:20413749 doi:10.1148/radiol.09090626

9 Ellegaard O, Wallin JA. The bibliometric analysis of scholarly production: How great is the impact? Scientometrics. 2015;105:1809-31. Medline:26594073 doi:10.1007/s11192-015-1645-z

10 Lehvo A, Nuutinen A. Finnish Science in International Comparison. A Bibliometric Analysis. Publications of the Academy of Finland; 15/2006. Helsinki, Academy of Finland.

11 Weingart P. Impact of bibliometrics upon the science system: Inadvertent consequences? Scientometrics. 2005;62:11731. doi:10.1007/s11192-005-0007-7

12 Akl EA, Meerpohl J, Raad D, Piaggio G, Mattioni M, Paggi M, et al. Effects of assessing the productivity of faculty in academic medical centres: a systematic review. CMAJ. 2012;184:E602-12. Medline:22641686 doi:10.1503/cmaj.111123

13 Kairouz VF, Raad D, Fudyma J, Curtis AB, Schünemann HJ, Akl EA. Assessment of faculty productivity in academic departments of medicine in the United States: a national survey. BMC Med Educ. 2014;14:205. Medline:25257232 doi:10.1186/1472-6920-14-205

14 League of Arab States, Member States of the Arab League. Available http://www.lasportal.org/ar/aboutlas/Pages/CountryData.aspx. Accessed: 22 January 2018.15.

15 World Bank. Data on Population. Available: https://data.worldbank.org/indicator/SP.POP.TOTL. Accessed: 22 January 2018.

16 Maziak W. Geography of biomedical publications. Lancet. 2004;363:490. Medline:14962534 doi:10.1016/S01406736(04)15500-1

17 El Ansari W, Afifi Soweid RA, Jabbour S. Geography of biomedical publications. Lancet. 2004;363:489-90. Medline:14962532 doi:10.1016/S0140-6736(04)15498-6

18 Bornmann L. Is collaboration among scientists related to the citation impact of papers because of their quality increases with collaboration? An analysis based on data from F1000Prime and normalized citation scores. J Assoc Inf Sci Technol. 2017;68:1036-47. doi:10.1002/asi.23728

19 Khor KA, Yu LG. Influence of international co-authorship on the research citation impact of young universities. Scientometrics. 2016;107:1095-110. Medline:27239078 doi:10.1007/s11192-016-1905-6

20 Figg WD, Dunn L, Liewehr DJ, Steinberg SM, Thurman PW, Barrett JC, et al. Scientific collaboration results in higher citation rates of published articles. Pharmacotherapy. 2006;26:759-67. Medline:16716129 doi:10.1592/phco.26.6.759

21 Oliver S, Bangpan M, Stansfielf C, Stewart R. Capacity for conducting systematic reviews in low- and middle-income countries: a rapid appraisal. Health Res Policy Syst. 2015;13:23. Medline:25928625 doi:10.1186/s12961-015-0012-0

22 Thelwall M, Kousha K. ResearchGate: Disseminating, communicating, and measuring scholarship? J Assoc Inf Sci Technol. 2015;66:876-89. doi:10.1002/asi.23236

23 Xia J, Lynette Myers R, Wilhoite S. Multiple open access availability and citation impact. J Inf Sci. 2011;37:19-28. doi: $10.1177 / 0165551510389358$

24 Thelwall M, Haustein S, Larivi冈re V, Sugimoto CR. Do altmetrics work? Twitter and ten other social web services. PLoS One. 2013;8:e64841. Medline:23724101 doi:10.1371/journal.pone.0064841 